\title{
Distribution of Currents in the Lightning Protective System of a Residential Building-Part I: Triggered-Lightning Experiments
}

\author{
Brian A. DeCarlo, Vladimir A. Rakov, Fellow, IEEE, Jason E. Jerauld, Member, IEEE, George H. Schnetzer, \\ Jens Schoene, Martin A. Uman, Fellow, IEEE, Keith J. Rambo, Venkateswararao Kodali, Douglas M. Jordan, \\ Guy Maxwell, Stephen Humeniuk, and Mark Morgan
}

\begin{abstract}
We present the results of structural lightning protective system (LPS) tests conducted in 2004 and 2005 at the International Center for Lightning Research and Testing (ICLRT) at Camp Blanding, FL. Lightning was triggered using the rocket-andwire technique, and its current was directly injected into the LPS. The test configurations in 2004 and 2005 differed in the lightning current injection point, number of down conductors, grounding system at the test house, and the use of surge protective devices. The primary objective was to examine the division of the injected lightning current between the grounding system of the test house, and remote ground accessible via the neutral of the power-supply cable. In 2004, the mean value of the peak current entering the electrical circuit neutral in search of its way to remote ground was about $22 \%$ of the injected lightning current peak, while in 2005 , it was about $59 \%$. For comparison, more than $80 \%$ of the injected peak current was observed to enter the electrical circuit neutral in similar 1997 tests at the ICLRT in which a different test house with a different (poorer) grounding system was used (Rakov et al. 2002 [1]). An attempt to model the 2004 and 2005 experiments is presented in a companion paper.
\end{abstract}

Index Terms-Grounding, lightning protective system (LPS), triggered lightning.

\section{INTRODUCTION}

I N 1997, the University of Florida (UF), using triggered lightning (e.g., Rakov, 1999 [2]) and a small test residential structure at the International Center for Lightning Research and Testing (ICLRT) at Camp Blanding, FL, examined two hypothetical scenarios suggested by the International Electrotechnical Commission (IEC) for the lightning current distribution in the electrical circuit of a residential building equipped with a lightning protective system when this system receives a direct strike.

In these two IEC scenarios, either 25 or $50 \%$ (the latter percentage is found in the IEC Standard IEC 62305-1 [3]) of the

Manuscript received August 7, 2007; revised October 19, 2007. Current version published September 24, 2008. This work was supported in part by the Lightning Safety Alliance (LSA) and in part by the National Science Foundation (NSF) under Grant ATM 0346164. Paper no. TPWRD-00499-2007.

B. A. DeCarlo, V. A. Rakov, J. E. Jerauld, G. H. Schnetzer, J. Schoene, M. A. Uman, K. J. Rambo, V. Kodali, and D. M. Jordan are with the Department of Electrical and Computer Engineering, University of Florida, Gainesville, FL 32611 USA (e-mail: rakov@ece.ufl.edu).

G. Maxwell, S. Humeniuk, and M. Morgan are with the Lightning Safety Alliance (LSA), Winsted, CT 06098 USA

Color versions of one or more of the figures in this paper are available online at http://ieeexplore.ieee.org.

Digital Object Identifier 10.1109/TPWRD.2008.917894 total lightning current is assumed to enter the building's electrical circuit neutral and to flow to the distribution transformer's ground and to other remote grounds in the system. It is important to note that the IEC current distributions assume that the current waveshapes in all parts of the circuit are the same, while in the 1997 experiment, the current waveshapes in the two ground rods (one ground rod for the lightning protective system and one for the power supply system) of the test house were observed to differ markedly from the current waveshapes in other parts of the test system. The grounding system of the 1997 test house was subjected to triggered-lightning discharges for three different configurations, with the house's electrical circuit (a utility meter followed by simulated resistive loads) being connected to the secondary of a pad-mount transformer, about $50 \mathrm{~m}$ distant. The primary of the transformer was connected to a $650-\mathrm{m}$ underground cable, which was open-circuited at the other end. The cable neutral was grounded at the transformer and at the open-circuited end. The test system was unenergized. Results of the 1997 experiment are presented by Rakov et al. 2002 [1]. The two ground rods at the 1997 test house appeared to filter out the higher frequency components of the lightning current, allowing the lower frequency components to enter the house's electrical circuit neutral. In other words, the ground rods exhibited a capacitive rather than the often expected and usually modeled purely resistive behavior. This effect was observed for dc resistances of the ground rods (in typical Florida sandy soil) ranging from more than a thousand ohms to some tens of ohms. The peak value of the current entering the 1997 test house's electrical circuit neutral was found to be more than $80 \%$ of the injected lightning current peak, in contrast with the 25 or $50 \%$ assumed in the two IEC-suggested scenarios.

A new test residential structure (see Fig. 1), typical of Florida housing, was constructed at the ICLRT in 2001. This structure (test house) was used in the triggered-lightning testing of structural lightning protection in 2004 and 2005. In both years, the test house was equipped with a lightning protective system (LPS) in accordance with the National Fire Protection Association standard (NFPA 780 [4]).

\section{EXPERIMENTAL SETUP}

\section{A. 2004 Experiment}

In 2004, the LPS, schematically shown in Fig. 2, was installed on the test house by a Lightning Safety Alliance (LSA) team. 


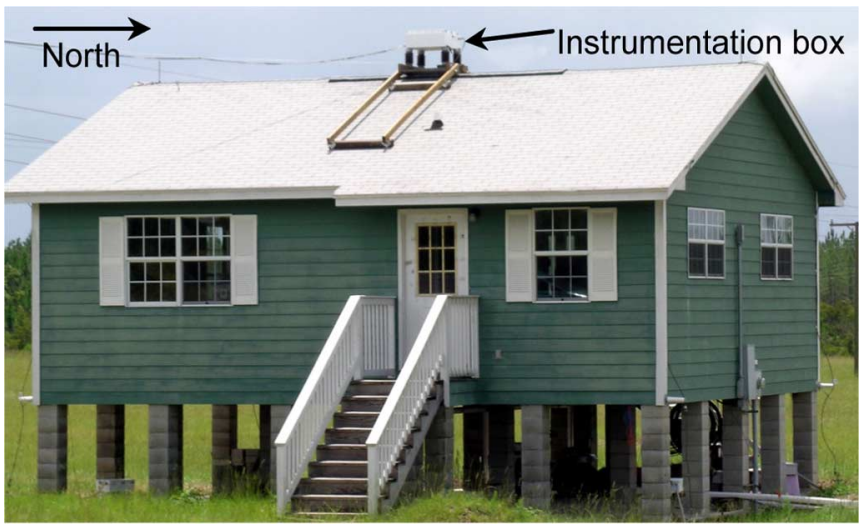

Fig. 1. Test house at the ICLRT whose LPS was subjected to direct lightning strikes in 2004 and 2005. Approximate dimensions of the house are $10 \times 7 \times 6.5$ $\mathrm{m}^{3}$. (Photo from 2005).

The lightning current was injected to one (south) of the three interconnected air terminals that were connected via two down conductors (downleads) to ground rods at opposite corners of the test house (see Fig. 2). There were two LPS ground rods at each of the SW and NE corners, separated by about $6.1 \mathrm{~m}$ and connected by a buried horizontal conductor. There was an additional power-supply system ground rod in the middle of the north side of the house. This ground rod was connected by a buried horizontal conductor approximately $3.4 \mathrm{~m}$ long to one of the NE corner LPS ground rods (see Fig. 2). An electrical diagram is shown in Fig. 3. The interior electrical wiring of the house was disconnected and replaced by a simulated load composed of two resistors (4 and $6 \Omega$ ) at the inside distribution box. MOV surge protective devices (SPDs) were installed between the two-phase conductors and the grounded neutral. A watt-hour meter was installed between the house electrical circuit and the underground power feeder (600-V triplexed cable). There was no power to the house, and the other end of the $600-\mathrm{V}$ cable was terminated at Instrumentation Station 1 (IS1), $50 \mathrm{~m}$ away, in $50-\Omega$ resistors. The cable's neutral was also grounded at IS1 using a single vertical ground rod with a length of $12 \mathrm{~m}$. The measured dc grounding resistance of the ground rod at IS1 was $69 \Omega$. The vertical ground rods at the test house had a length of $2.7 \mathrm{~m}$, with a dc grounding resistances for each grounding location being given in Fig. 3. The dc grounding resistance of the entire system before its burying was $130 \Omega$ and for the entire system buried $113 \Omega$. Grounding resistances were measured using the fall-of-potential method.

Currents were measured at six points, labeled A, B, C, D, G, and $\mathrm{K}$ (see Figs. 2 and 3). Points A and B were on downleads at two opposite corners of the house. Point $\mathrm{C}$ was the powersupply system ground, and point $\mathrm{G}$ was the ground at IS1. Point $\mathrm{D}$ is on the ground conductor from the power entry box (service entrance panel) down to the power-supply system ground rod. A Pearson 110A current transformer was used to measure the current at point $\mathrm{K}$, and $1-\mathrm{m} \Omega$ shunts were used at points $\mathrm{A}, \mathrm{B}$, $\mathrm{C}, \mathrm{D}$, and $\mathrm{G}$.

The lightning current was directed, via a 32-m-long metallic conductor, from the tower launcher to one (south) of the three test house air terminals (see Fig. 2).

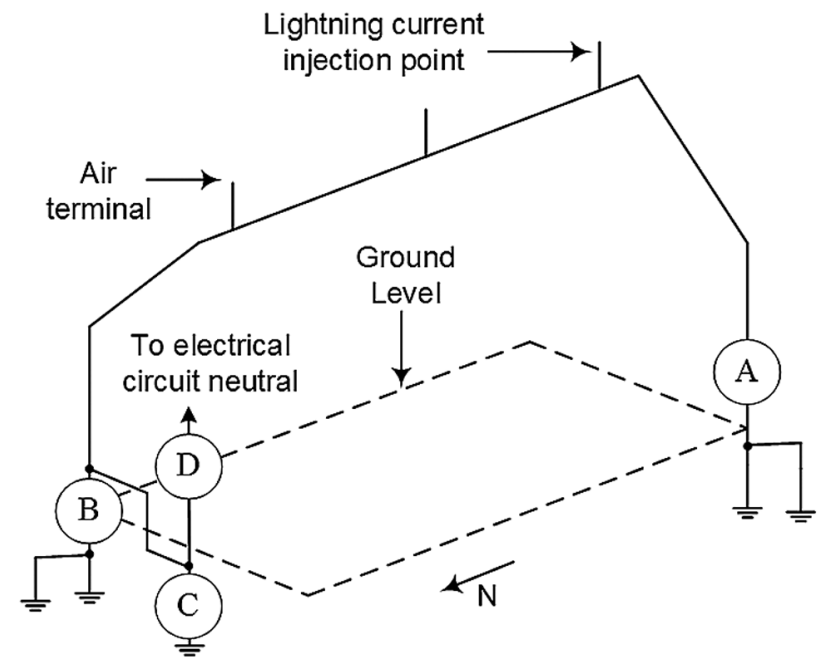

Fig. 2. Diagram of the lightning protective system of the test house in 2004. All conductors below the plane labeled "Ground Level" are buried (in direct contact with earth). See also Fig. 3.

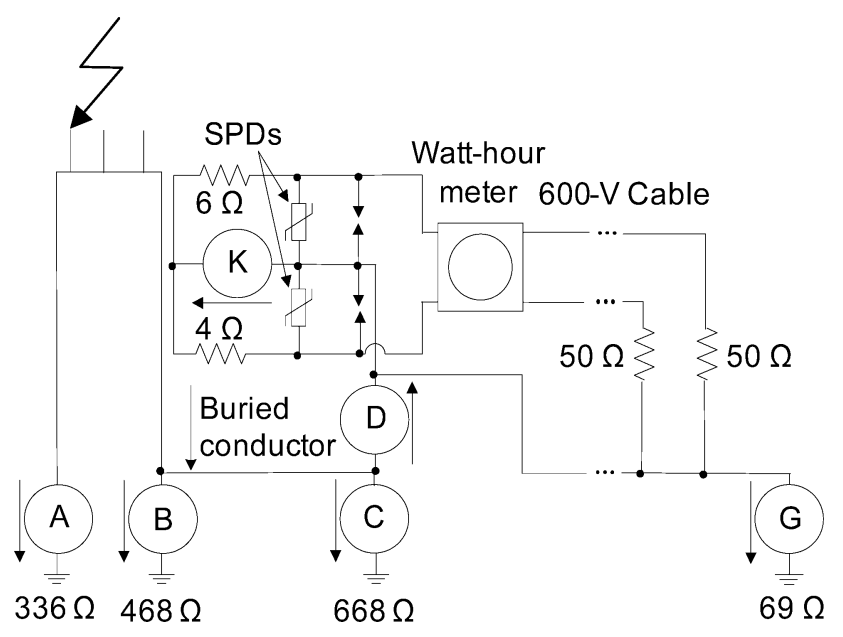

Fig. 3. Electrical diagram of test system configuration for 2004. Currents A, $\mathrm{B}, \mathrm{C}, \mathrm{D}$, and $\mathrm{K}$ were measured at the test house, and current $\mathrm{G}$ was measured at IS1, $50 \mathrm{~m}$ away.

\section{B. 2005 Experiment}

The LPS for the 2005 experiment was a modification to the LPS installed in 2004. The 2005 setup consisted of two interconnected air terminals, four down conductors, and five ground rods (four for the LPS and one for the power-supply system) interconnected by a buried loop conductor referred to as a ring grounding electrode or, sometimes, a counterpoise (see Fig. 4). An electrical diagram is shown in Fig. 5. LPS vertical ground rods each had a length of $2.7 \mathrm{~m}$, with dc grounding resistances being given in Fig. 5. The power-supply system ground rod had a length of $3 \mathrm{~m}$ and a measured grounding resistance of $524 \Omega$. The dc grounding resistance of the entire test house grounding system buried was $121 \Omega$. The dc grounding resistance of the ground rod at IS1 was $69 \Omega$. As in 2004, the test system was unenergized.

Currents were measured at six points, labeled A, A1, B, B1, $D$, and $G$ (see Figs. 4 and 5). One-m $\Omega$ shunts were used to measure current at all the points. 


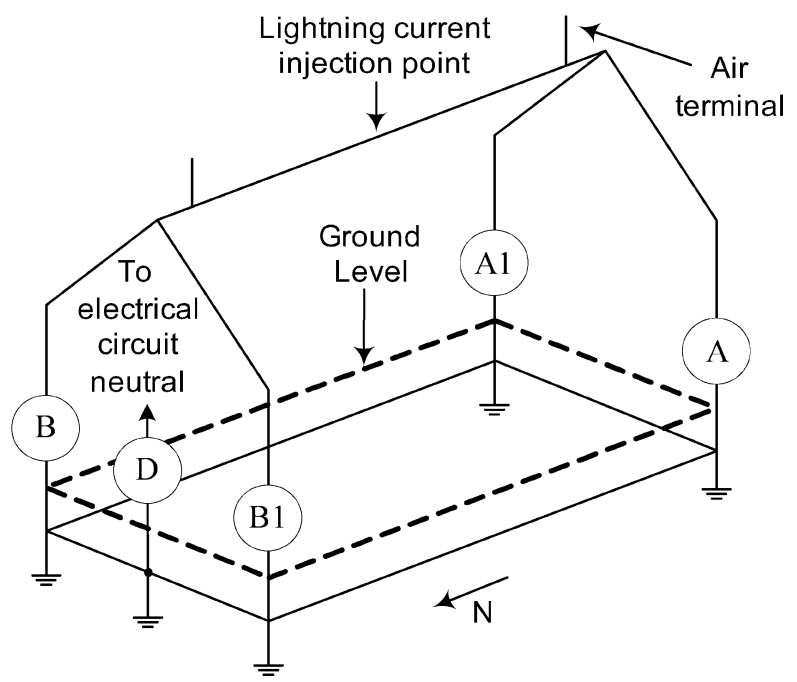

Fig. 4. Diagram of the lightning protective system of the test house in 2005 . All conductors below the plane labeled "Ground Level" are buried (in direct contact with the earth). See also Fig. 5.

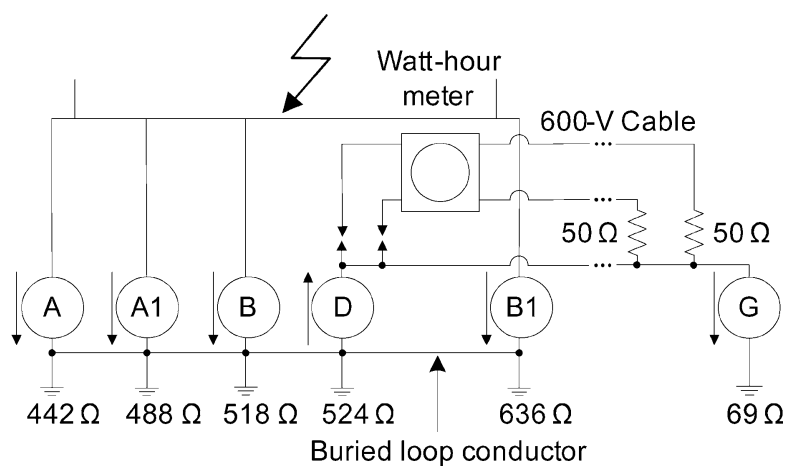

Fig. 5. Electrical diagram of the test system configuration for 2005. Currents A, $\mathrm{A} 1, \mathrm{~B}, \mathrm{~B} 1$, and D were measured at the test house, and current $\mathrm{G}$ was measured at IS1, $50 \mathrm{~m}$ away.

The lightning current was directed from the tower launcher, via an instrumentation box located at the former position of the 2004 middle air terminal (removed in 2005) on the roof of the test house (see Fig. 1), to the horizontal conductor connecting the two 2005 LPS air terminals.

In both 2004 and 2005, Nicolet Isobe 3000 fiber-optic links were used to transmit signals from the sensors (1-m $\Omega$ shunt or current transformer) to the digital storage oscilloscopes (DSOs) in the Launch Control trailer. Two types of DSOs-a Yokogawa DL716 (2-s record length) and LeCroy Waverunner LT344L (5-ms record length) were used. The Yokogawa and LeCroy data were sampled at 2 and $20 \mathrm{MHz}$, respectively. The Yokogawa triggered once per flash, while the LeCroy could trigger up to ten times per flash.

\section{DATA}

\section{A. 2004 Experiment}

In 2004, two lightning flashes were triggered to the test house, both on June 23, 2004. One flash contained nine and the other two leader/return stroke sequences. Both flashes were triggered using the tower launcher and effectively transported negative
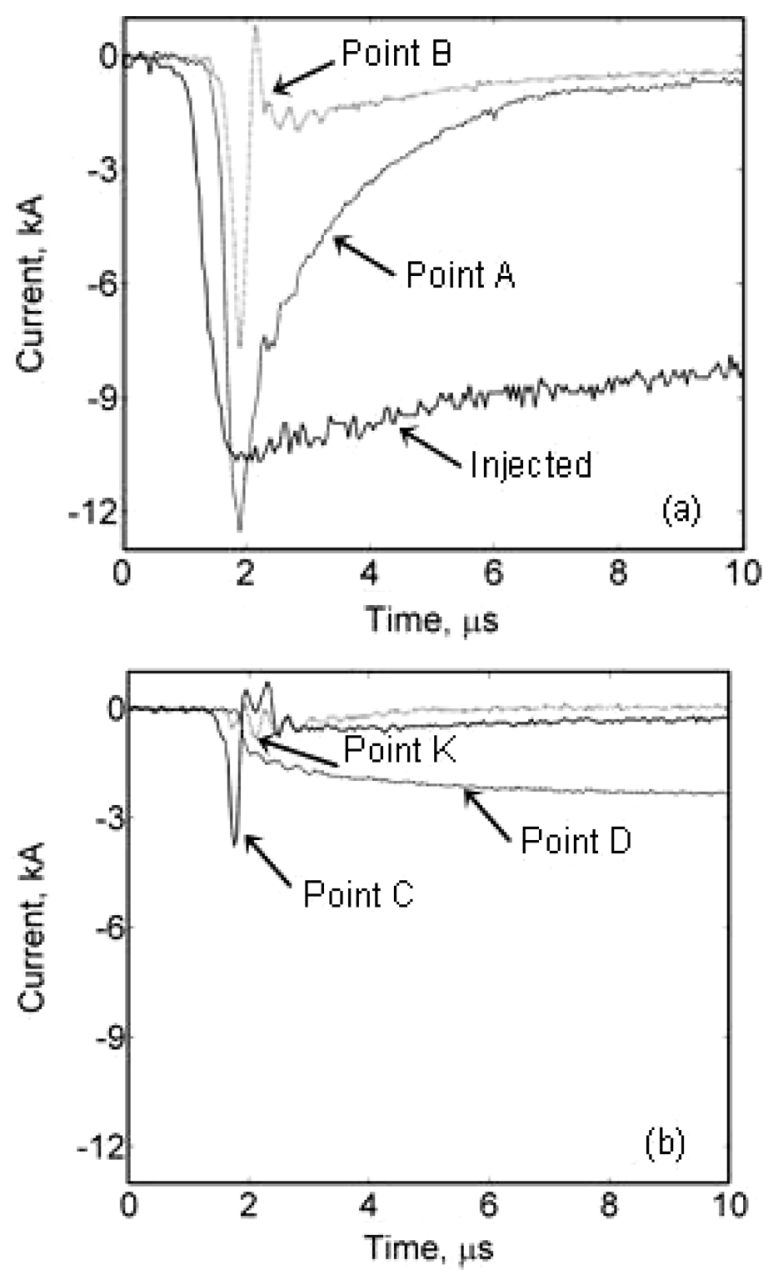

Fig. 6. Return-stroke currents for stroke $0401-3$, displayed on a $10-\mu$ s time scale. (a) Injected current and currents at points A and B. (b) Currents at points C, D, and K (see Fig. 3).

charge to ground. The initial stage current [2] was directed to ground at the tower base, so that it did not enter the LPS of the test house. The return-stroke peak currents ranged from 3.6 to $17.8 \mathrm{kA}$.

Injected lightning current and currents at points $\mathrm{A}, \mathrm{B}$, and $\mathrm{C}$, and currents at points $\mathrm{D}$ and $\mathrm{K}$ for stroke 3 of a nine-stroke flash 0401 are shown in Fig. 6 [injected, A, and B in (a) and C, D, and $\mathrm{K}$ in (b)].

\section{B. 2005 Experiment}

In 2005, from July 15, 2005 to August 7, 2005, eight flashes were triggered for the test house experiment, including six flashes containing eight return strokes, and two flashes containing the initial stage (IS) current only. Both the IS and return-stroke currents were injected in the LPS. Return-stroke peak currents ranged from $6.8 \mathrm{kA}$ to $34 \mathrm{kA}$. Examples of data from the 2005 experiment for one stroke (0521-1) are shown in Figs. 7-11.

In Fig. 7, the IS current (not well resolved in this figure) has a magnitude of tens to hundreds of amperes and a duration in excess of $100 \mathrm{~ms}$. There is a no-current interval of some tens of milliseconds between the end of the IS current and the returnstroke pulse (labeled Stroke 1 in Fig. 7). 


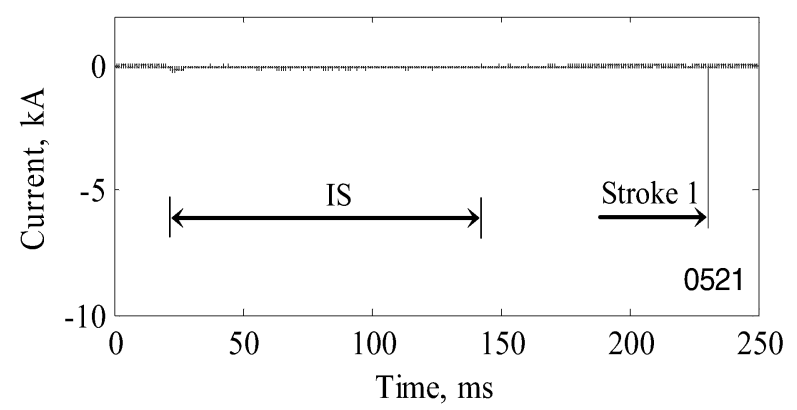

Fig. 7. Injected current measured at the roof of the test house for single-stroke flash 0521 , displayed on a $250-\mathrm{ms}$ time scale. IS = Initial stage of rocket-triggered lightning.
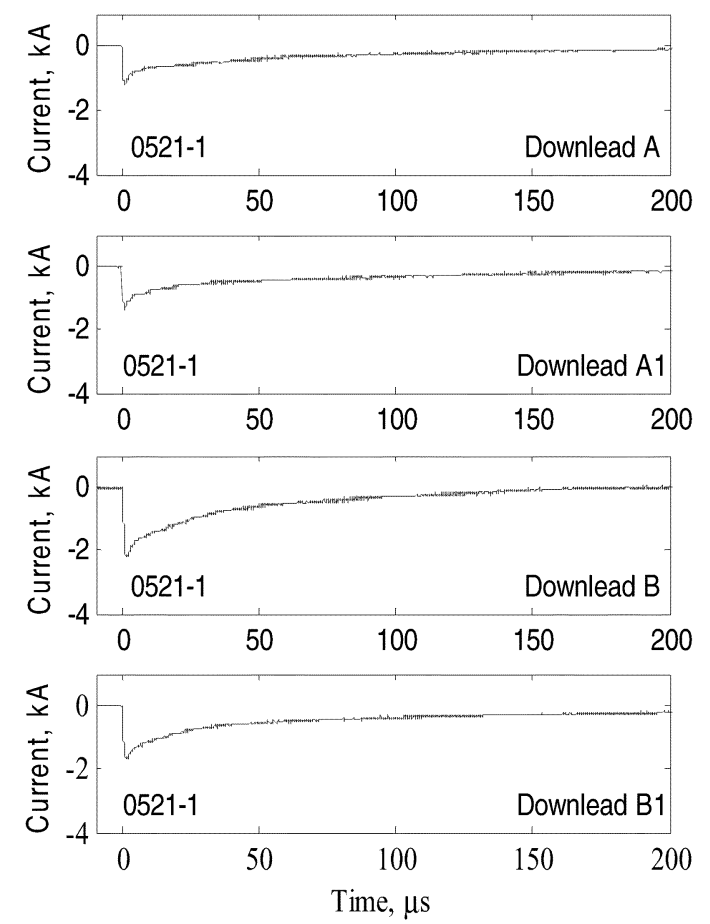

Fig. 8. Return stroke currents in four downleads for stroke 0512-1, displayed on a $210-\mu$ s time scale. From the top to bottom, downlead A, downlead A1, downlead B, downlead B1 (see Figs. 4 and 5).

\section{ANALYSIS AND DISCUSSION}

\section{A. 2004 Experiment}

Return-stroke peak currents and current half-peak widths (HPW) at different measurement points for nine strokes of flash 0401 are shown in Figs. 12 and 13, respectively. Currents to ground rods at the test house exhibited considerably smaller half-peak width than either injected current or the current at point D (see Fig. 13). This is consistent with the 1997 experiment [1]. Thus, higher-frequency current components tend to flow to ground locally, while lower-frequency components travel to remote ground at IS1, $50 \mathrm{~m}$ away. Note that some lower-frequency components apparently entered the ground via the buried horizontal conductor connecting ground rods B and C. Bejleri et al. [5] reported, from a different experiment, that vertical ground rods connected to a counterpoise (buried horizontal loop conductor) tended to dissipate primarily

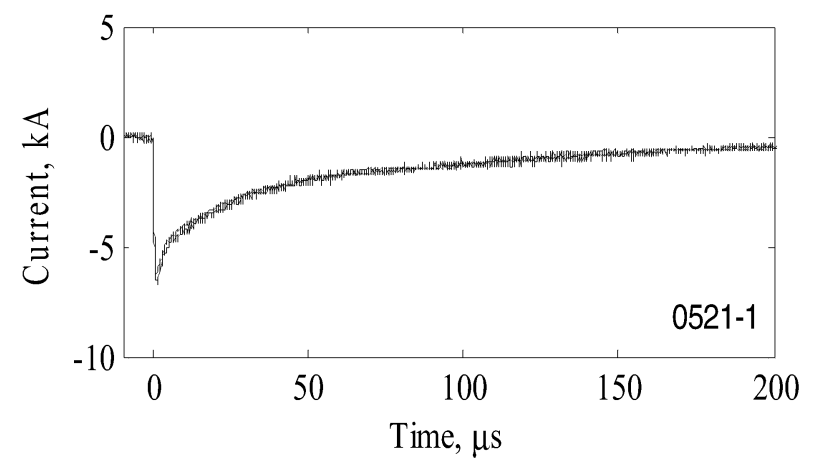

Fig. 9. Sum of the four downlead currents (A, A1, B, and B1) for stroke 0521-1 (see Fig. 8), displayed on a $210-\mu$ s time scale. Also shown is the injected current waveform which is indistinguishable from the sum of four downlead current waveforms.

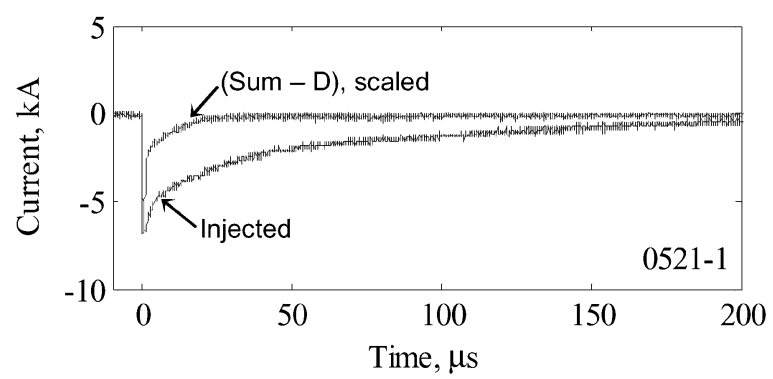

Fig. 10. Comparison of injected return stroke current and the difference between the sum of the four downlead currents and current D, labeled (Sum-D), for stroke $0521-1$, displayed on a $210-\mu$ s time scale. Note that the difference waveform was scaled so that its peak is equal to that of the injected current, for a direct comparison of their waveshapes. The (Sum-D) waveform represents the current going to the grounding system of the test house.

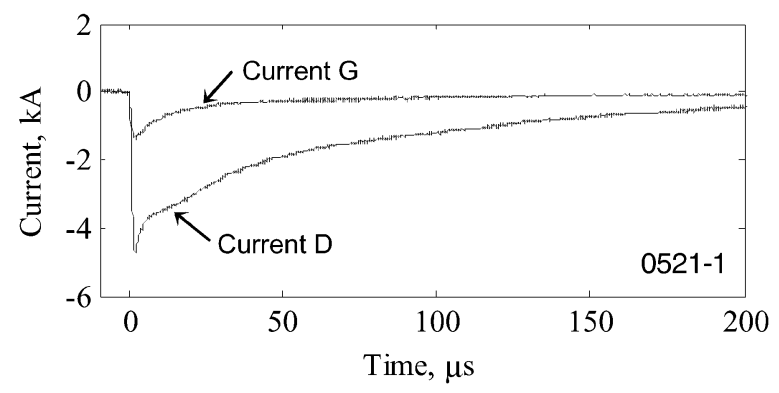

Fig. 11. Comparison of current D and current $\mathrm{G}$ for stroke 0521-1, displayed on a $210-\mu$ s time scale.

higher-frequency components, while lower-frequency components were primarily dissipated by the counterpoise. Additional reasons for the observed differences in current waveshapes in different parts of the circuit (see Fig. 3) will be discussed in the next paragraph.

The current at point A (SW grounding location at the test house, which is closest to the current injection point) is typically the largest, even larger than the injected current. This could be due to electromagnetic coupling to the large vertical loop (some tens of square meters) formed by the conductors of the lightning protective system of the test house (see Fig. 2) and, additionally, could be due to electromagnetic coupling to the measuring circuit (primarily the fiber-optic transmitter inside 


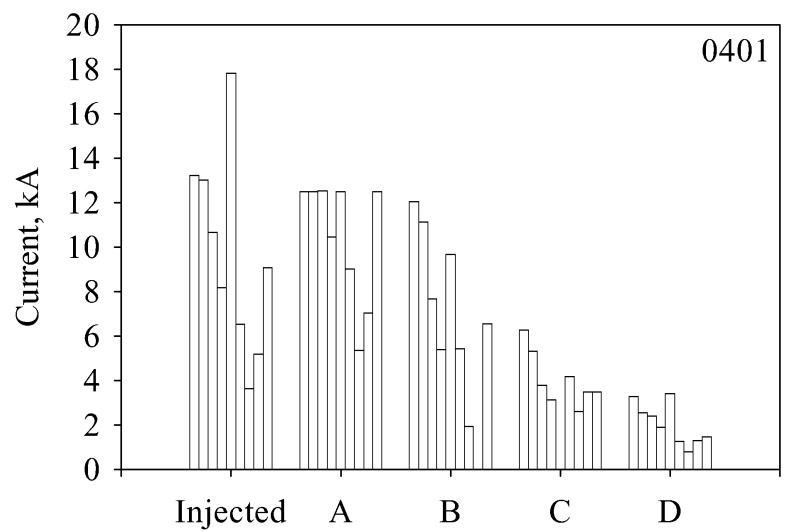

Fig. 12. Return-stroke peak current at different measurement points for strokes 1 through 9 (in ascending order from left to right) of flash 0401. A, B, C, and D are measurement points indicated in Fig. 3.

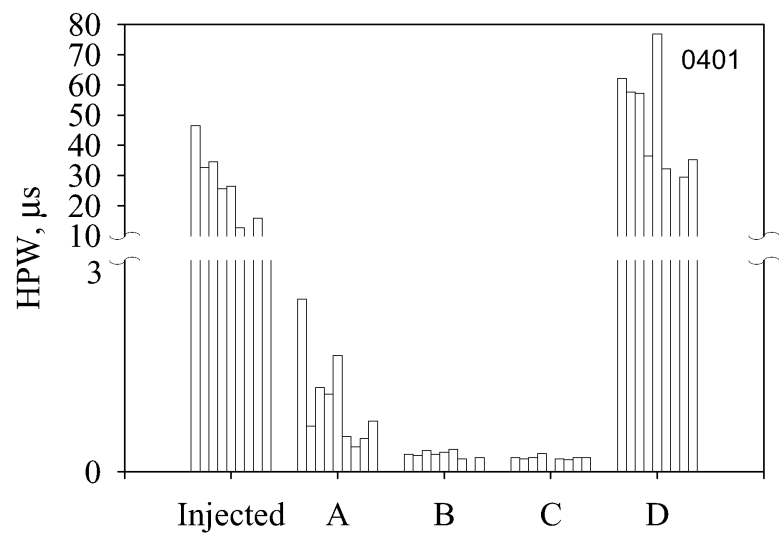

Fig. 13. Current half-peak width (HPW) at different measurement points for strokes 1 through 9 (in ascending order from left to right) of flash 0401. Refer to Fig. 12 for the horizontal axis legend. Note that the vertical axis is broken at 3 to $10 \mu \mathrm{s}$.

a not-properly-latched metallic enclosure placed near the current sensor). The coupling to the LPS hypothesis is supported by the fact that current waveforms at point $\mathrm{A}$ are considerably narrower than incident current waveforms (see Fig. 6) and often appear as the time derivative of the incident current (see also companion paper). Peak values of the injected current and the current entering the electrical circuit neutral in its search for remote ground (current D) for 2004 are characterized in Table I. Peak value of current $D$ in percent of the injected peak current varied from 16 to $28 \%$, with a mean value of $22 \%$, which is significantly lower than the over $80 \%$ in the 1997 experiment. The difference is apparently due to much better grounding of the test house in 2004.

Currents measured at point $\mathrm{G}$ (ground rod at IS1) were corrupted due to arcing from the instrumentation metallic enclosure, which was connected to the IS1 ground rod, to a grounded (buried, bare-neutral) power cable that was part of another experiment. However, current at point D (assumed to be equal to the current entering the neutral of the $600-\mathrm{V}$ cable) can be viewed as a proxy for current at point $G$, provided that there was no insulation breakdown along the cable. For one stroke (0401-7), arcing at IS1 did not occur during the initial $6 \mu$ s or so, and, as a result, current at point $\mathrm{G}$ was not corrupted during
TABLE I

Peak Value of CuRrent d Versus Injected Peak CurRent for RETURN STROKES IN FlaSHES TRIGGERED IN SUMMER 2004

\begin{tabular}{llll}
\hline \hline Characteristics & $\begin{array}{l}\text { Injected } \\
\text { Current, } \\
\mathrm{kA}\end{array}$ & $\begin{array}{l}\text { Current D, } \\
\mathrm{kA}\end{array}$ & $\begin{array}{l}\text { Current } \mathrm{D} \\
\text { relative to } \\
\text { Injected } \\
\text { Current, \% }\end{array}$ \\
\hline Minimum & 3.6 & 0.8 & 16 \\
\hline Maximum & 17.8 & 3.4 & 28 \\
\hline Arithmetic Mean & 9.4 & 2.1 & 22 \\
\hline Standard Deviation & 4.1 & 0.9 & 3.6 \\
\hline Geometric Mean & 4.7 & 1.9 & 22 \\
\hline Sample Size & 11 & 11 & 11 \\
\hline \hline
\end{tabular}

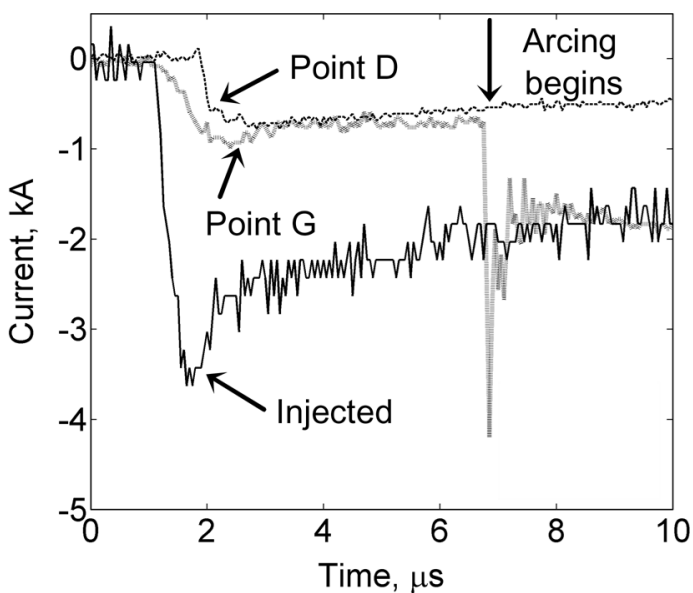

Fig. 14. Injected return stroke current and currents at points D and G (see Fig. 3 ) for stroke $0401-3$, displayed on a $10-\mu$ s time scale. Note that currents D and $\mathrm{G}$ are similar during the first $6 \mu \mathrm{s}$, prior to arcing at IS1.

this time interval and could be compared to the corresponding current at point D (see Fig. 14). As seen in Fig. 14, currents at points $D$ and $G$ are very similar during the initial $6 \mu$ s or so, suggesting that no insulation breakdown occurred along the $600-\mathrm{V}$ cable. It is worth noting that stroke $0401-7$ was the smallest one (injected peak current of $3.6 \mathrm{kA}$; see Table I). Other strokes had peak currents up to $17.8 \mathrm{kA}$ (see Fig. 12 for peak current), and larger strokes could well cause a breakdown of the cable's insulation, as was observed in the 1997 [1] and 2005 (to be discussed in Section B) in experiments.

\section{B. 2005 Experiment}

Results of the 2005 experiment are illustrated in Figs. 7-11 and Figs. 15-17, which show current waveforms and their parameters for stroke 1 of flash 0521 . This was a single-stroke flash as seen in the overall current record shown in Fig. 7. Current waveforms measured in all four downleads: A, A1, B, and B1 are presented in Fig. 8. Note that the distribution of the injected current among the four downleads is more uniform than in 2004 (between two downleads, A and B; see Figs. 2 and 3), in part due to the difference in current injection point. As expected, the sum of four downlead current waveforms matches well with the injected current waveform (see Fig. 9). The sum of four downlead currents minus the current at point $D$ represents the current going to the grounding system of the test house, the latter being 


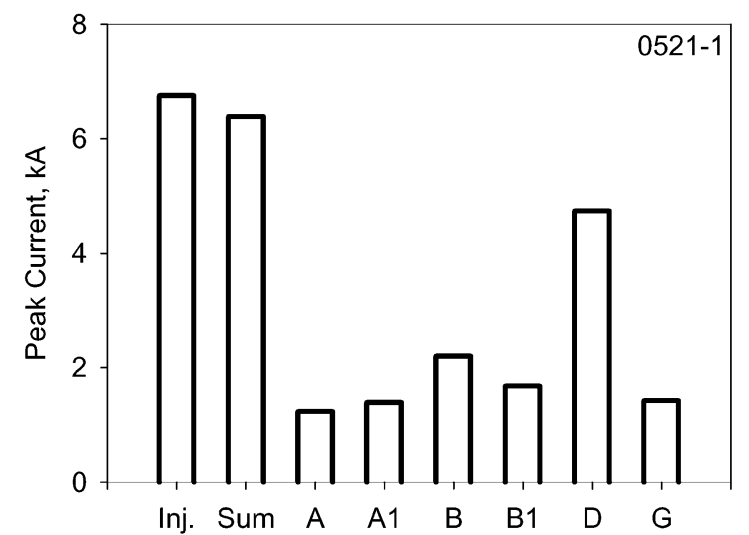

Fig. 15. Return-stroke peak current at different measurement points for stroke 0521-1. Inj. = Injected current. Sum = sum of four downlead currents (A, A1, B, B1). D and G are currents at measurement points indicated in Fig. 5.

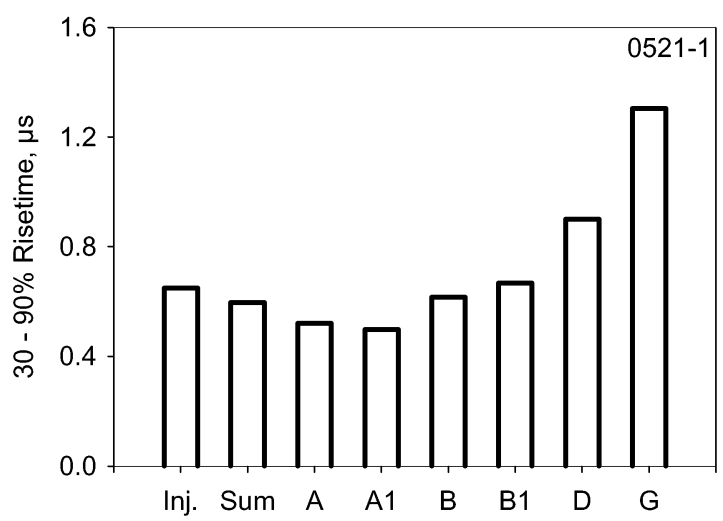

Fig. 16. The 30-90\% current risetime at different measurement points for stroke 0521-1. Refer to Fig. 15 for the horizontal axis legend.

compared to the injected current in Fig. 10. Note that the current to the grounding system of the test house, (Sum-D) in Fig. 10, is normalized to the injected current in order to compare only the waveshapes. It is clear from Fig. 10 that the lower-frequency components associated with the tail of the injected current do not go to the grounding system of the test house and have to find their way to the remote ground (at IS1), accessible via the neutral of the power-supply cable. Currents at points D (to the house's electrical circuit neutral) and $\mathrm{G}$ (to the remote ground) are compared in Fig. 11. The difference between these two currents is likely to be due to the breakdown of and leakage through the insulation of the buried $600-\mathrm{V}$ power-supply cable.

Peak values of the injected current and the current entering the electrical circuit neutral (current D) for 2005 are characterized in Table II. Peak values of current D in percent of the injected peak current varied from 51 to $72 \%$ with a mean value of $59 \%$. Thus, in 2005 , more than a factor of two larger percentage of total lightning current was forced to find its way to the remote ground than in 2004. This is a somewhat unexpected result, since the grounding system of the test house in 2005 was presumably better than in 2004: five vertical ground rods interconnected by a buried loop conductor (counterpoise) for a total length of about $37 \mathrm{~m}$ versus two groups (two or three) of vertical ground rods, each group interconnected by a buried horizontal conductor (or conductors) for a total length of about $15.6 \mathrm{~m}$.

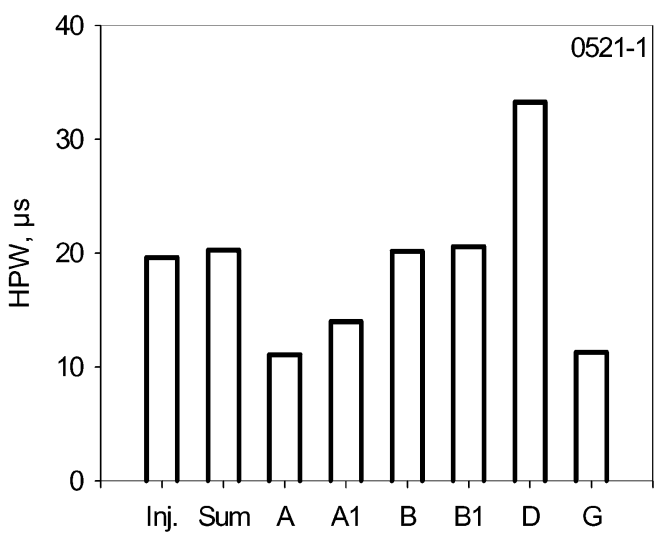

Fig. 17. Current half-peak width (HPW) at different measurement points for stroke 0521-1. Refer to Fig. 15 for the horizontal axis legend.

TABLE II

Peak Value of Current D versus InJected Peak Current For RETURN STROKES IN FLASHES TRIGGERED IN SUMMER 2005

\begin{tabular}{llll}
\hline \hline Characteristics & $\begin{array}{l}\text { Injected } \\
\text { Current, kA }\end{array}$ & $\begin{array}{l}\text { Current } \\
\mathrm{D}, \mathrm{kA}\end{array}$ & $\begin{array}{l}\text { Current } \mathrm{D} \\
\text { relative to } \\
\text { Injected } \\
\text { Current, \% }\end{array}$ \\
\hline Minimum & 6.8 & 4.4 & 51 \\
\hline Maximum & 34 & 8.5 & 72 \\
\hline Arithmetic Mean & 14 & 6.6 & 59 \\
\hline Standard Deviation & 8.8 & 1.8 & 8.5 \\
\hline Geometric Mean & 13 & 6.1 & 58 \\
\hline Sample Size & 8 & 7 & 7 \\
\hline \hline
\end{tabular}

The apparently poorer LPS performance in 2005 , compared to 2004, seems to be inconsistent with the notion that a buried loop conductor (employed in 2005) represents a superior grounding system relative to short radials (employed in 2004). Reasons for this unexpected result are presently unknown.

In 2005, SPDs and simulated loads were disconnected from the electrical circuit. As a result, the watt-hour meter (protected only by built-in spark gaps) showed signs of electrical arcing and burning, with evidence of metal being melted both inside and outside the meter. The absence of load apparently did not significantly influence the overall current distribution, since most of the current tends to flow along the neutral toward the remote ground (compare currents $\mathrm{K}$ and D in Fig. 6).

There were signs of arcing between a phase conductor and the neutral conductor of the $600-\mathrm{V}$ triplexed cable inside the watthour meter box, specifically to the metal conductor plugs (on the rear of the meter). There was also damage to the insulation of the $600-\mathrm{V}$ cable, probably allowing some current to leak from cable's conductors to the ground. The two phase conductors of the cable had ten and eight holes melted through their insulation, and the neutral conductor insulation had three holes. The holes measured from 3 to $4 \mathrm{~mm}$ in diameter. There were other signs of damage on the $600-\mathrm{V}$ cable insulation, including pitting, surface melting, and circular demarcations, all indicative of electrical arcing. Some of the damage to the $600-\mathrm{V}$ cable might have been caused by the 2004 strikes (the cable was not excavated after 2004 testing). For comparison, in 1997, the 600-V cable had 
about 40 holes in the insulation of its neutral conductor. This cable was replaced with a new one before 2004 testing.

In the absence of SPDs in 2005, the watt-hour meter incurred damage, similar to the no-SPD configuration tested in 1997 [1]).

\section{SUMMARY}

We have presented results of structural LPS tests conducted in 2004 and 2005 at the ICLRT at Camp Blanding, FL. Lightning was triggered using the rocket-and-wire technique (e.g., Rakov 1999 [2]) and its current was directly injected into the LPS. The test configurations in 2004 and 2005 differed in the lightning current injection point, number of down conductors (downleads), grounding system at the test house, and the use of SPDs. The primary objective was to examine the division of the injected lightning current between the grounding system of the test house and remote ground accessible via the neutral of the power-supply cable. In 2004 (two pairs of interconnected LPS ground rods plus a bonded power-supply system rod), the mean value of the peak current entering the electrical circuit neutral was about $22 \%$ of the injected lightning current peak, while in 2005 (four LPS ground rods plus power-supply system rod, all interconnected by a buried loop conductor), it was about $59 \%$. For comparison, more than $80 \%$ of the injected peak current was observed to enter the electrical circuit neutral in similar 1997 tests (one LPS ground rod interconnected with a power-supply system rod) at the ICLRT, in which a different test house was used. The 1997 grounding system was clearly poorer than in either 2004 or 2005, which is consistent with the observed poorer LPS performance in 1997. However, the apparently poorer LPS performance in 2005, compared to 2004, seems to be inconsistent with the notion that a buried loop conductor (employed in 2005) represents a superior grounding system relative to short radials (employed in 2004). The reasons for this unexpected result are presently unknown. In absence of SPDs in 2005, the watt-hour meter incurred damage, similar to the no-SPD configuration tested in 1997 [1].

\section{REFERENCES}

[1] V. A. Rakov, M. A. Uman, M. I. Fernandez, C. T. Mata, K. J. Rambo, M. V. Stapleton, and R. R. Sutil, "Direct lightning strikes to the lightning protective system of a residential building: Triggered-lightning experiments," IEEE Trans. Power Del., vol. 17, no. 2, pp. 575-586, Apr. 2002.

[2] V. A. Rakov, "Lightning discharges triggered using rocket-and-wire techniques," Recent Res. Devel. Geophys., vol. 2, pp. 141-171, Research Signpost, India.

[3] Protection Against Lightning, Part 1: General Principles, IEC-62305-1 2006.

[4] "Standard for the installation of lightning protection system," NFPA 780, Available from NFPA (National Fire Protection Assoc.). Qunicy, MA, 2004.

[5] M. Bejleri, V. A. Rakov, M. A. Uman, K. J. Rambo, C. T. Mata, and M. I. Fernandez, "Triggered lightning testing of an airport runway lighting system," IEEE Trans. Electromagn, Compat., vol. 46, no. 1, pp. 96-101, Feb. 2004.

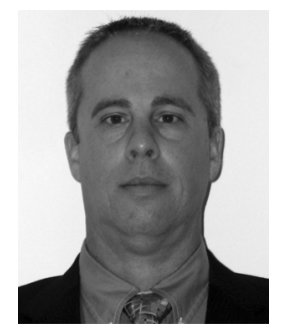

Brian A. DeCarlo received the B.S. and M.S. degrees in electrical engineering from the Department of Electrical and Computer Engineering at the University of Florida (UF), Gainesville, in 2002 and 2006, respectively.

From 2002 to 2006, he was a Research Assistant with the UF Lightning Research Laboratory. In 2004 he was in charge of a lightning electric field measuring station in Gainesville, FL, and in 2005, he participated in rocket-triggered lightning experiments at the International Center for Lightning Research and Testing (ICLRT), Camp Blanding, FL, studying the effectiveness of a residential lightning protective system. He is author or coauthor of several papers and technical reports. Currently, he is with Sikorsky Aircraft Corporation, Stratford, $\mathrm{CT}$, where he is involved with lightning protection of aircrafts.

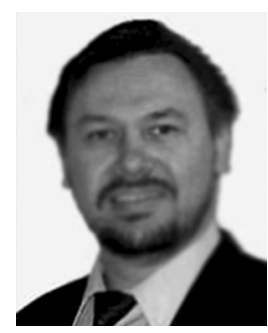

Vladimir A. Rakov (SM'96-F'03) received the M.S. and Ph.D. degrees in electrical engineering from the Tomsk Polytechnic University, Tomsk, Russia, in 1977 and 1983, respectively.

From 1977 to 1979, he was an Assistant Professor of electrical engineering at Tomsk Polytechnic University. In 1978, he became involved in lightning research at the High Voltage Research Institute, where from 1984 to 1994, he was Director of the Lightning Research Laboratory. Currently, he is a Professor in the Department of Electrical and Computer Engineering, University of Florida, Gainesville, and Codirector of the International Center for Lightning Research and Testing (ICLRT). He is the author or coauthor of one book, ten book chapters, over 30 patents, and more than 400 papers and technical reports on various aspects of lightning, with over 150 papers being published in reviewed journals.

Dr. Rakov is the Chairman of the Technical Committee on Lightning of the Biennial International Zurich Symposium on Electromagnetic Compatibility and Former Chairman of the AGU Committee on Atmospheric and Space Electricity (CASE). He is a Fellow of IEEE, AMS, and IET and a member of AGU, $\mathrm{SAE}$, and ASEE.

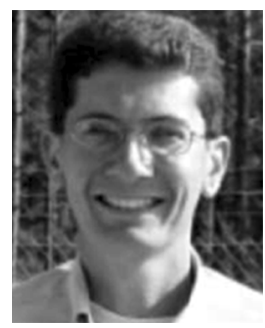

Jason E. Jerauld (M'98) received the B.S., M.S. and $\mathrm{Ph} . \mathrm{D}$. degrees in electrical engineering from the University of Florida, Gainesville. in 2001, 2003, and 2007, respectively.

From 2001 to 2005, he participated in natural and rocket-triggered lightning experiments at the International Center for Lightning Research and Testing (ICLRT), Camp Blanding, FL. During 2005, he was Assistant Director for Operations and Experiments at the ICLRT, supervising the summer research program. He is the author or coauthor of more than 70 papers and technical reports on various aspects of lightning, with over 20 papers being published in reviewed journals. In 2008, he joined Raytheon Missile Systems, Tucson, AZ, as a Senior Electrical Engineer, focusing on antenna design and the electrical analysis of radomes.

Dr. Jerauld is the recipient of the 2004-2007 NASA Florida Space Grant Consortium Fellowship.

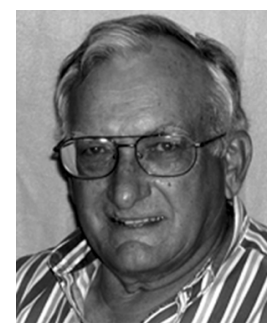

George H. Schnetzer received the B.S.E.E. degree from the University of Missouri, Rolla, in 1962 and the M.S.E.E. degree from the University of New Mexico, Albuquerque, in 1965.

He was with Sandia National Laboratories from 1962 to 1973 and from 1974 to his retirement. From 1973 to 1974, he was an Antenna Design and Development Engineer with Boeing Co., Seattle. WA. During his tenure at Sandia, he worked primarily in the areas of antenna development, radar system development, and electromagnetic testing. He holds a patent for an omnidirectional horizontally polarized antenna and has published several reports on antenna design, propagation experiments, and electromagnetic tests. 


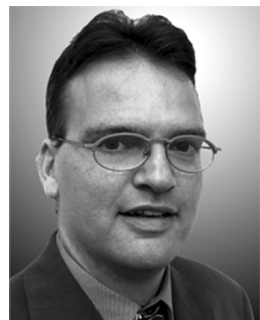

Jens Schoene received the Dipl.-Ing. degree from the University of Paderborn, Department Soest, Germany in 1999. He received the M.S. and Ph.D. degrees from the University of Florida, Gainesville, in 2002 and 2007, respectively.

From 1999 to 2006, he was a Research Assistant at the International Center for Lightning Research and Testing (ICLRT), Camp Blanding, FL In 2007, he joined EnerNex, Knoxville, TN, as a Power Systems Engineer. His research areas are the responses of power distribution systems to direct and nearby lightning strikes, the modeling of the lightning return stroke process, and the characterization of the lightning electromagnetic environment. He is the author or coauthor of more than 30 papers or technical reports, with 13 papers being published in reviewed journals.

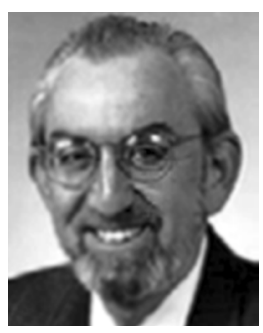

Martin A. Uman (F'88) received the Ph.D. degree from Princeton University, Princeton, NJ, in 1961.

He is Distinguished Professor in the University of Florida's Department of Electrical and Computer Engineering. He has written five books on the subject of lightning, as well as a book on plasma physics, and has published more than 180 papers in reviewed journals. He holds six patents, five in the area of lightning detection and location. He was an Associate Professor of Electrical Engineering at the University of Arizona, Tucson, from 1961 to 1964 . He joined the University of Florida faculty in 1971 after working for seven years as a Fellow Physicist at Westinghouse Research Labs, Pittsburgh, PA.

Dr. Uman cofounded and served as President of Lightning Location and Protection Inc. (LLP) from 1975 to 1985 . He is the recipient of the 1996 IEEE Heinrich Hertz Medal for outstanding contributions to the understanding of lightning electromagnetics and its application to lightning detection and protection" and the 2001 AGU John Adam Fleming Medal for original research and technical leadership in geomagnetism, atmospheric electricity, space science, aeronomy, and related sciences: for outstanding contribution to the description and understanding of electricity and magnetism of the Earth and its atmosphere." Dr. Uman is a Fellow of the AGU and the AMS.

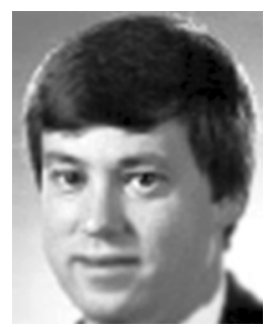

Keith J. Rambo received the B.S.E.E. degree from the University of Florida (UF), Gainesville, in 1978.

As an undergraduate, he worked in the UF Lightning Research Laboratory. From 1979 to 1983 , he was Senior Process Development Engineer of Intel Corporation, Santa Clara, CA. From 1983 through 1986, he was a Product Line Manager for Xicor, responsible for all aspects of wafer fabrication. In 1986, he joined the UF Department of Electrical and Computer Engineering where he has been Director of Technical Support Services since 1989. Since 1994, Mr. Rambo has been heavily involved in triggered lightning experiments at Camp Blanding, Florida. He has authored ten technical publications.
Venkateswararao Kodali, photograph and biography not available at the time of publication.

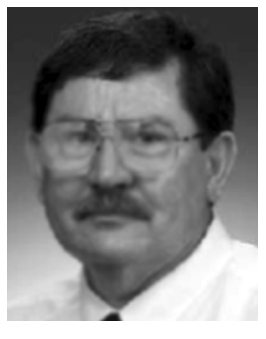

Douglas M. Jordan received the Ph.D. degree from the University of Florida, Gainesville, in 1990.

$\mathrm{He}$ was a founding faculty member of the University of North Florida Electrical and Computer Engineering Department and the University of West Florida Electrical and Computer Engineering Department. In 2000, he returned to the Gainesville campus of the University of Florida as a Lecturer and Undergraduate Coordinator. Currently, he is a Senior Lecturer and continues research on the optical and electromagnetic properties of lightning.

Guy Maxwell, photograph and biography not available at the time of publication.

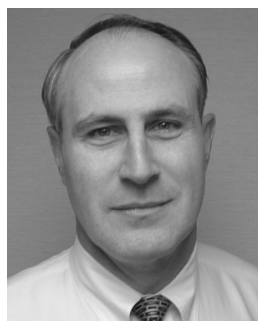

Stephen Humeniuk received the B.A. degree from Wheaton College, Wheaton, IL.

$\mathrm{He}$ has been with the Warren Lightning Rod Company for approximately 15 years, served as Vice President for nine years, and is currently President. Mr. Humeniuk also serves on the Lightning Protection Institute's (LPI) Board of Directors. He is an LPI Certified Master Installer/Designer. For the past ten years, he has served on the board of the United Lightning Protection Association (ULPA), with two years as Vice President, and two years as President.

Mr. Humeniuk is a member of the International Electrotechnical Commission's (IEC) Lightning Protection Technical Committee No. 81. He is a founding member and the Vice President of the Lightning Safety Alliance (LSA). He is a member of the Technical Committee for National Fire Protection Association's Standard for the Installation of Lightning Protection Systems (NFPA 780).

Mark Morgan, photograph and biography not available at the time of publication. 